\title{
Analysing the Playground: Sensitizing Concepts to Inform Systems That Promote Playful Interaction
}

\author{
Stefan Rennick Egglestone ${ }^{1}$, Brendan Walker ${ }^{2}$, Joe Marshall ${ }^{1}$, \\ Steve Benford ${ }^{1}$, and Derek McAuley ${ }^{1}$ \\ ${ }^{1}$ Horizon Digital Economy Research \\ Sir Colin Campbell Building, University of Nottingham Innovation Park \\ Triumph Road, Nottingham, NG7 2TU \\ \{sre, jom, sdb, drm\}@cs.nott.ac.uk \\ ${ }^{2}$ Aerial \\ 258 Globe Road, London, E2 0JD, UK \\ info@aerial.fm
}

\begin{abstract}
Playful interaction in an important topic in HCI research, and there is an ongoing debate about the fundamental principles that underpin playful systems. This paper makes a contribution to this debate by outlining a set of sensitizing concepts which have emerged from an analysis of interaction in the playground; these help explain its appeal to children, and have been selected for their potential to inspire the design of future playful systems. These concepts have emerged from the analysis of material collected during a structured workshop which was organized by the authors, and which was attended by a group of experts. They have also been applied to the design of Breathless, a playful interactive system which has recently been deployed by the authors, and which represents an unusual evolution of the playground swing. The paper concludes with a number of reflections inspired by Breathless. These have been structured through the use of the concepts as an analytical tool.
\end{abstract}

Keywords: Playground, playful interaction, sensitizing concepts.

\section{Introduction}

Playful interaction has been a topic of HCI research for some time, and a variety of authors have provided contributions that have helped shape design. Gaver, for example, has considered aspects of playful interaction that relate to ludic [1] activities such as exploration, invention and wonder [2], whilst Bekker, Sturm and Eggen have emphasised the importance of both physical and social aspects of playful interaction [3], suggesting a set of values that underpin them, and describing a set of systems that illustrate the application of these values to design. Although some studies have focused on playful interactions between children and computing technology [4], play is an activity that can be beneficial for humans of all ages, and there is a growing strand of research focused on design-led investigations into systems that exploit playful interaction to provide beneficial effects. A significant example is the use of gaming systems to promote whole-body interaction and rehabilitation for individuals 
who have acquired physical disability. Here, technological approaches have ranged from immersive virtual-reality systems [5] to commodity gaming consoles such as the Nintendo Wii [6], with the latter becoming regularly used by professional therapists to support individual rehabilitation in both clinical and domestic settings.

Within this broad area of research, the authors have previously pursued a series of design-led investigations that have been inspired by the theme-park environment, and which have resulted in the deployment of systems with which participants have demonstrated a variety of different types of playful interaction. In Fairground: Thrill Laboratory, a number of volunteers were fitted with a telemetry system that captured aspects of their experience on a thrilling ride and transmitted it back to a live audience [7]. Transmitted information included video of the rider's face and quantifications of their physiological responses to the ride; observations and interview analysis have since revealed examples of riders using these systems in a playful way, either by choosing to perform to an unseen audience through the video feed, or by trying to play games with their own physiological response, in the knowledge that it was being observed and interpreted by others. More recently, we have constructed the Broncomatic, a novel, small-scale ride that rotates left and right in response to the direction of a rider's breathing; this has been embedded into a strenuous, competitive game which encourages competitive social interaction between participants [8].

However, in tandem with such design-led interventions, we have recently engaged in research into the principles of systems that promote playful interaction, and a presentation of the outcomes of this research is the central contribution of this paper. Working within a framework that focuses on physical and social aspects of play, we have chosen to shape our contribution by studying the playground, a form of entertainment for children which is incredibly popular in most countries, and which has recently emerged as a target of interest within HCI research. Our approach has been to use data collected during a carefully-structured workshop to develop a set of sensitizing concepts that help explain the specific appeal of the playground as a place where children can take part in playful interaction, but which have the potential to inspire the future design of systems that feature playful interaction. We present these concepts in section 5 of this paper, and then illustrate their creative potential in section 6 by discussing their relationship to the design of Breathless, a public event constructed around a novel interactive installation which has been designed by the authors, and which represents a dramatic evolution of the playground swing. Firstly, however, section 2 provides a description of the playground and considers relevant research, and section 3 describes the methodological basis of the work presented in this paper, with a focus on the use of sensitizing concepts to make a contribution to knowledge. Section 4 then provides an overview of the structure and proceedings of the workshop that we organised. After the presentation of sensitizing concepts, we then discuss knowledge that has been gained in relationship to them through an analysis of data collected during Breathless. Finally, the paper concludes with more general reflections inspired by these concepts, and with a brief discussion of the topic of future research structured around them. 


\section{The Playground}

The playground is a term that has a variety of meanings across different cultures. For the purposes of this paper, we have constrained the scope of our research by only considering playgrounds that have been designed for children and which are situated outdoors. This differentiates the playground from the park, a space reserved for the leisure of the wider population [9], and from the trend to provide playgrounds that are targeted at adults [10]. Of course, playgrounds may be situated in parks, and adults may have a role in the activities that take place in them, but our focus is on spaces that have been designed with the needs of children in mind. Our rationale is that the design of such spaces has a long and well-documented history, especially in relation to playgrounds intended for urban spaces [11], and, in the UK at least ${ }^{1}$, the provision of playgrounds for children has been taken as a shared responsibility of local and national government. This means that there is currently an active community of professionals with a substantial expertise in playground design, as evidenced by the existence of companies that design and construct playgrounds [12]. The playground is also a current topic of research within a variety of academic disciplines, including child development [13] and educational psychology [14]. Given this level of external expertise, the challenge for the authors has been to design a research process that focuses on enabling the integration of prior expertise into HCI research, rather than focusing on a process that generates new knowledge in its own right. Section 3 of this paper describes the methods that we have chosen for this task, and the remainder of this paper considers the results that have been produced by it.

The design of playgrounds for children is also an active area of HCI research, much of which focuses on augmenting playgrounds with interactive features. Much of this research has been constructed around an explicit manifesto of encouraging physical exercise and social interaction, motivated by the need to reduce childhood obesity and to increase social contact (for example, [15]). However, there are also examples of interactive playground equipment that have just been designed to provide interesting new affordances for play [16], rather than changing lifestyles. Within this research effort, Sturm et al [15] have classified potential interventions, using two different set of dimensions. The first relates to the type of intervention that can be made; categories include installations of interactive technologies (such as interactive water games [17]), interactive props (such as the LEDball [15], an object that lights up in various colours when shaken or rotated), and interactive surfaces (such as the ADA floor [18], which can sense people, and respond with different colours of light). A second set of dimensions relates to key design challenges, namely: social interaction, simplicity, challenge, providing goals and feedback. Using the terminology of these two frameworks, the workshop described in the next section primarily focuses on playground interactions that are orientated around installations, rather than props or surfaces. The deliverables of this workshop are set of sensitizing concepts that suggest approaches to design, and which might therefore be considered complimentary to the design challenges set out by Sturm et al, though they are intended to be more widely applicable than just the playground.

\footnotetext{
${ }^{1}$ All authors are resident in the UK.
} 
Other examples of HCI or design research in the playground mostly relate to specific interventions that have been made. For example, the Interactive Slide [19] is a large, inflatable slide, intended for use by multiple children, with an interactive surface created using a projector and a video camera, whilst the Interactive Pathway [16] consists of a weight-sensitive pathway which children can stand on, causing various playful actions to occur. An example of an interactive prop is provided by Misund et al [20], who describe an augmented version of a traditional "chase and catch" game. Derakhshan et al [21] describe the use of artificial neural networks to categorise the behaviour of children who are playing on an interactive surface.

\section{Research Methods}

As noted previously in this paper, a substantial body of academic expertise in relation to the playground already exists. Therefore, in attempting to understand the appeal of the playground, and to generate knowledge that can inform the future development of playful interactive systems, our approach has been to focus on synthesizing and presenting existing knowledge, through the medium of a focused workshop. This was attended by experts from a variety of backgrounds, and its primary purpose has been an examination of the playground from a number of perspectives. The proceedings and structure of this workshop are described in section 4 below.

Material gathered during this workshop has since been analysed by the authors. Informed by a rich tradition of qualitative research, these analyses have been structured to generate a set of sensitizing concepts, which are presented in section 5 . Sensitizing concepts are analytical constructs that "give the user a general sense of reference" [22] and which can guide attention to particular events or behaviours [23]. They are a tool that is commonly used in areas of research that require the understanding of people and their interactions, including anthropology, sociology and health-care [24]. They are also a tool with a long history of use within research that has impacted on HCI. An example is provided by Crabtree et al [25], who present a set of sensitizing concepts which identify classes of location in the home that are amenable to computation interventions. Such concepts have then inspired the design of systems such as the Drift Table [26] and LINC [27], an electronic family calendar. Sensitizing concepts presented in this paper are intended to explain the success of rides in the playground, in order to inspire future playful systems.

Having presented a set of sensitizing concepts, section 6 illustrates their creative application by considering Breathless, a novel installation which represents a dramatic evolution of a playground swing, and which was constructed by the authors. The design and construction of Breathless was led by a professional designer, who drew on the sensitizing concepts presented in section 5 for inspiration, and who integrated a variety of other source materials. Breathless was experienced by more than 50 participants, and a variety of documentary material was gathered in relation to their experience and the running of the event. An analysis of this material is presented in section 6 , where it contributes practical knowledge in relation to the sensitizing concepts outlined in section 5 . 


\section{Workshop Proceedings}

As stated in section 2, the focus of our workshop was on understanding the appeal of the static installations that are commonly found in playgrounds. In the UK, these tend to include swings, roundabouts, slides, zip-wires and see-saws. Since playground equipment may vary around the world, representative images of these are shown in figure 1. To ensure that any outputs of this workshop were useful to the research community, we were careful to select a group of participants with relevant professional or academic expertise. These included:

- a professional playground designer from Free Play, a company that focuses on the integration of research into playground design practice [28]

- members of the Learning Sciences Research Institute [29] at the University of Nottingham who had previously conducted research orientated around play

- an experienced ethnographer who had conducted a study of playful interaction

- individuals with relevant expertise in interaction design

- individuals with relevant expertise in HCI

- individuals with relevant expertise in psychology

The workshop was led by a design consultant from Aerial, a company specialising in the design and construction of thrilling experiences [30]. It lasted for a day, and was divided into three sessions, each of which involved work that took place in small groups. Each session began with a short talk by an invited expert, and then involved time to work on a task that was set by the workshop leader. Tasks were designed to draw on the knowledge and experience of participants, both as professionals or academics, but also as adults with personal experience of playgrounds, either as children themselves, or as the parents of children. Tasks were designed to produce tangible outputs, to aid the analysis processes that were planned at the conclusion of the workshop. Tasks were also designed to require both analytical and creative though processes, with the intention of inspiring participants to think about the playground in a variety of different ways, aiming to produce a level of analysis that was suitably deep to make a useful contribution to HCI. The proceedings of each task were recorded in a variety of ways by the authors of this paper, and have since been analysed. The following sessions and tasks took place in this workshop:

\section{Session One}

This session began with a talk by a professional playground designer, who described designs that he had produced, and participatory design methods that he had adopted. Participants of the workshop were then split into groups, and each was allocated two of the pieces of equipment that are featured in figure 1 below. For each, participants were provided with a sheet of representative images as a stimulus, and were asked to draw on their personal and professional experience to produce a description of the appeal of each ride. During this session, participants assembled a number of large paper sheets to which post-it notes had been attached, which were then collected by the workshop organisers. Participants also presented their thoughts to the group. Video-cameras were used to capture these presentations for later analysis. 


\section{Session Two}

Different groups were formed for this session, and each was assigned a single type of ride to think about, from the selection shown in figure 1. Participants were then asked to design a novel ride inspired by this, using only mechanical technologies. Participants were provided with sheets of paper to sketch their designs on, which were later collected by workshop organisers. Participants were also asked to present their ideas to the whole group, and these were again captured on video.

\section{Session Three}

Given the authors previous work on playful technologies which sensed the responses of participants (see section 1), this session began with a talk by an expert, who described a broad range of available sensing technologies, and motivated their use. Participants were then reformed into different groups, and each was given a single type of ride to work on. Participants were then asked to design a novel ride which was inspired by this, but which integrated electronic sensing technologies in some form. For this activity, participants were explicitly told that they could think beyond the boundaries of the playground, and were provided with a selection of materials to construct models of their designs from. As before, group presentations were videorecorded, and photographs of all models constructed by participants were taken. Participants were then given the opportunity to talk about any thoughts that they had in relation to the workshop, which concluded after this session.

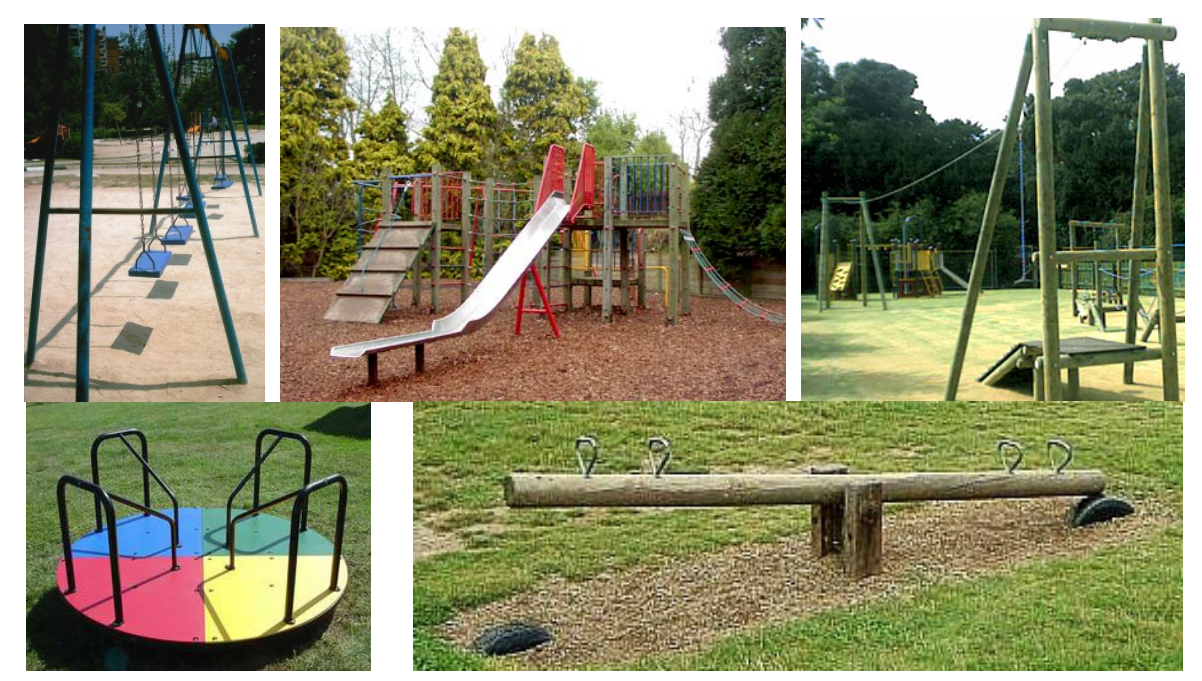

Fig. 1. Play equipment commonly found in UK playgrounds. (Clockwise from top left) Swings, slide, zip-wire, roundabout, see-saw.

\section{Sensitizing Concepts}

After the workshop, the authors discussed the meaning of the data that had been collected, focusing on trying to understand how our participants thought about the 
playground. A thematic analysis [31] then led to the sensitizing concepts presented in this section. These have been selected to provide a novel perspective on play in the playground, and for their potential to inspire the future design of playful systems. Each is accompanied by a description drawn from material generated by the workshop, which is intended to support its comprehension by the reader.

\section{Danger and Fear Are Important Playground Experiences}

Many of our participants spoke of exhilarating playground experiences that involved them performing dangerous activities, or being scared of the situations they had got themselves into. Participants talked about using swings as launchers, allowing them to fly through the air and land on the ground, sometimes causing themselves injury, but more normally just enjoying the thrill and pleasure of using their bodies to provide such momentary experiences. Participants also talked about spinning too quickly on roundabouts, worrying about flying off, but being exhilarated by the physical challenge of hanging on despite centrifugal forces. The professional playground designer who introduced the first session talked about expensive playgrounds which had been "KFCed" - Kitted, Fitted and Carpetted for safety - and which were almost always underused because of this. Participants also talked about the social fears that could be created by interactions between the different age groups that might use a playground, but focused on the importance of such situations for learning how to interact in a social environment. In particular, playing with the older children on a ride for the first time was seen as a scary but important social barrier to overcome by some participants, and an important part of the process of growing up.

\section{Loss of Control Is a Key Component of Playground Installations}

Our participants considered that some of the exhilaration described in relation to the previous concept is provided by the loss of control that is inherent in many rides. This is obvious on an installation such as a zip wire, where, after launching, the rider allows themselves to be controlled by gravity, potentially leading to an exciting ride experience whose duration can barely be influenced. Loss of control can be part of the experience of taking part in a swing, since a rider can be pushed higher and higher by someone standing on the ground, allowing them the thrill of exceeding their own comfort zone in a way which they may not be able to manage on their own. The sharing of control is a key part of the experience of a see-saw, in which control oscillates in a rhythmic way between the two participants, both of whom have some control over, and some responsibility for, the others safety during this cycle. Participants also considered loss of control to be an important part of the roundabout experience, as a rider who had boarded a roundabout could then be spun faster and faster by those standing on the ground, causing them to have to hang, fall off or take the risk of jumping off and potentially injuring themselves.

\section{Play Often Involves the Re-appropriation of Installations in Unexpected Ways}

Participants talked about re-appropriation as a key issue, and described examples of it leading to enjoyable forms of play. Participants talked about the fun of using a swing in ways for which it was not designed, either by trying to swing left and right (rather than forwards or backwards), by trying to balance on it in unusual ways, by getting several people to ride the swing at once, or by using it as a launcher. One participant 
described a game in which he lay on the ground underneath a swing seat, which was then thrown towards his head. The chains attached to the seat would restrain it, but the play of the game involved flinching as little as possible as it was thrown. There were many other examples of appropriation that were given during the workshop, including the re-appropriation of equipment by older groups of children for "social loafing", therefore allowing them to exert control over access to it by younger children. A form of re-appropriation that was emphasised by the professional playground designers was that of fantasy - i.e. children using their imagination to think of the playground in different ways, such as a magical forest. Interestingly, the slide as a piece of playground equipment was criticised by a number of participants as having little potential for re-appropriation, although children could still climb backwards up it.

\section{Installations That Cater to Different Levels of Skill Can Support Long-Term Play}

Many playgrounds are used by children with very different ages, and different (and often rapidly developing) levels of physical ability. Playgrounds, although simple, often maintain their level of interest across many years of a child's life, and our participants considered this to be a beneficial product of the very different levels of skill that could be used on a variety of items of equipment in a playground. For example, a very young child might just enjoy sitting in a swing, under the control of a parent, whilst an older child might enjoy learning to control the movements of their body, in order to swing higher than before. A very developed child might then enjoy the physical challenge of standing on a moving swing. Pushing others on swings is also a playful activity that children of many ages and levels of ability could engage in. As well as being playful and fun, such interactions with playgrounds have the potential to assist the learning of new motor skills, with positive benefits for the development of children. Many of the re-appropriations of playground equipment that participants considered also involved a high level of skill for mastery, and developing a new skill was seen as part of the fun of taking part in these activities.

\section{Different Designs of Rides Offer Very Different Throughputs}

Playgrounds are rarely managed environments, and the throughput inherent to particular rides has an impact on the experience of using them. For example, a slide has a fairly clear trajectory [32] in which a participant starts at the top and slides down, unless it is re-appropriated by children who wish to climb back up. Such a trajectory is likely to maintain a high throughput, as the duration of each experience is limited by the length of the slide. In contrast, a roundabout or swing can be used in an open-ended way, and participants may only get off when tired. Such open-ended trajectories may allow participants to experiment with their experience in a playful way, but may cause frustration for other children who are denied access to a quickly moving roundabout or an occupied swing for a long period of time.

\section{Spectatorship and Performance Are an Important Part of the Experience of Play} Many discussions of playground equipment focused on the rider, but spectatorship was also seen as an important role in play, albeit often a transitory one. For example, a child who was trying to push themselves higher and higher on a swing might gain even more enjoyment and motivation if being watched by a peer or a parent, and a 
spectator who was a child might be inspired to gain a new skill by watching others in the playground performing on rides. Spectatorship is also part of the social interaction in a playground, and there could be some tension between a child who is controlling a piece of equipment, and who wants to carry on using it, and a child who is watching the ride and wanting to use it. Equally, the control of a ride by a social group could be seen as a visible display of power, with understanding how to subvert such power on the part of a spectator being an important social lesson.

Table 1. Summary of sensitizing concepts from the playground, with key elements highlighted in first column

\begin{tabular}{|l|l|}
\hline Danger and fear & $\begin{array}{l}\text { The excitement provided by a level of danger and fear is } \\
\text { important to the success of playgrounds. }\end{array}$ \\
\hline Control & $\begin{array}{l}\text { Losing control and being pushed past your comfort level is a } \\
\text { key component of some playground installations. }\end{array}$ \\
\hline Re-appropriation & $\begin{array}{l}\text { As part of imaginary and exploratory play, installations are } \\
\text { often re-appropriated for purposes that they were not designed } \\
\text { for. }\end{array}$ \\
\hline Skill & $\begin{array}{l}\text { Catering for different levels of skill and development is } \\
\text { important for supporting long-term play. }\end{array}$ \\
\hline Throughput & $\begin{array}{l}\text { Different designs of rides offer very different throughputs, } \\
\text { which affects the social use of these rides. }\end{array}$ \\
\hline $\begin{array}{l}\text { Spectatorship } \\
\text { and performance }\end{array}$ & $\begin{array}{l}\text { Watching others on rides, and demonstrating or showing off } \\
\text { when on the ride are important parts of playground interaction. }\end{array}$ \\
\hline
\end{tabular}

\section{Knowledge Gained through Study of a Novel System}

Section 5 has described a set of sensitizing concepts developed from a workshop themed around the playground, which are intended to provide inspiration for the design of systems that promote physical and social interaction. In keeping with the traditions of this method, we would expect these concepts to be modified, challenged or re-appropriated by ourselves and others as they are integrated into future work. As part of this process, this paper now presents an account of our initial work in applying them, as part of a process which led to Breathless, an installation which was assembled in the autumn of 2010, and which was publicly deployed on a single evening. We begin this section with a description of Breathless, and then present an analysis of material collected during its deployment, which is used to highlight the relationship between this installation and the set of concepts presented in section 5 . This paper then concludes with a broader discussion of the practical knowledge that has been gained in applying these concepts, and by considering future work in relation to the development of our sensitizing concepts.

\subsection{Overview of Breathless}

Breathless is an experience constructed around a very large rope swing, which is driven by a powerful electric wheelchair motor controlled by a computer. Figure 2 
illustrates the use of this motor to drive a horizontal rope, which in turn transfers energy directly into the rope swing, and therefore affects its movements. For its first deployment, the swing was suspended from the covered roof of an outdoor exhibition space. The horizontal rope made use of two pulleys attached to pillars.

In keeping with the Broncomatic [8] which was described in the introduction to this paper, in Breathless, the movement of the horizontal rope is influenced by the breathing of the rider. In particular, breathing in causes the rope to move one way, and breathing out causes it to move the other way. As such, breathing in synchronization with the natural oscillations of the swing causes it to go higher, whilst breathing out of synchronisation caused it to judder and go lower. The length of the vertical rope that connects the swing seat to the loading point in the ceiling of the space is calculated to create a resonant frequency of $5 \mathrm{~Hz}$ (i.e. 12 breaths per minute, which is a natural rate of breathing for humans at rest). The idea is to create an experience that responds strongly to breathing that is in harmony with it, but which feels uncomfortable given breathing that is not in harmony.

Breathless uses a modified gas mask to monitor the breathing of participants, through a custom-designed filter which is screwed into a port in the mask. An image of a participant wearing one of the masks is shown on the left of figure 3 . This features a participant who is lying in a custom-made cradle which replaces the seat or knot more commonly found at the bottom of a rope swing. This is designed to make it difficult for a participant to transfer energy into the swing through movements of their body, ensuring that the swing is controlled through the breathing of participants alone.

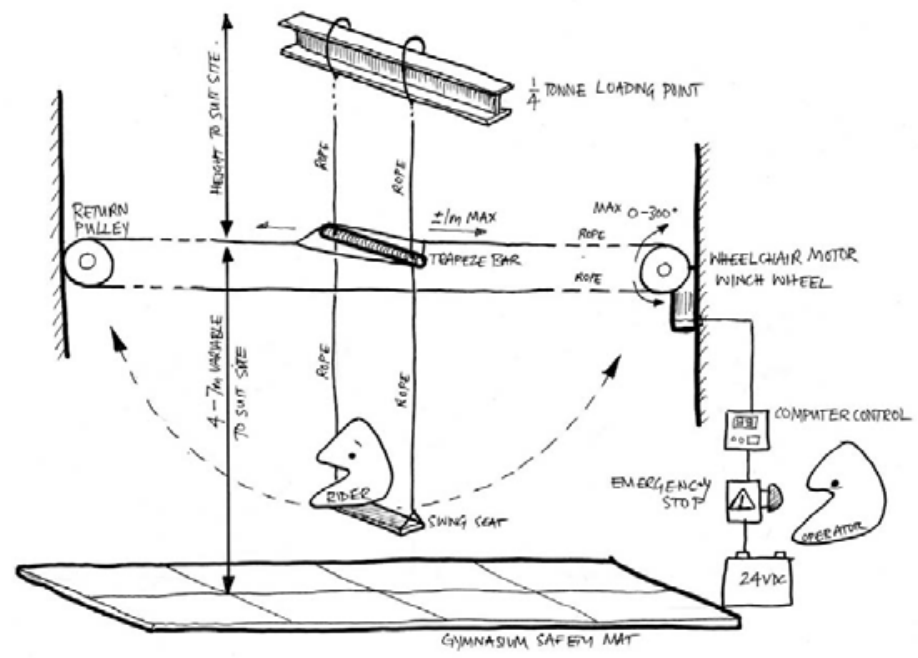

Fig. 2. Illustration of mechanism of rope swing

In addition to the unique form of interaction provided by the mechanism described above, the experience of taking part in Breathless is heightened by the structure and theming of the event, which together create an intense experience with a strong sense 

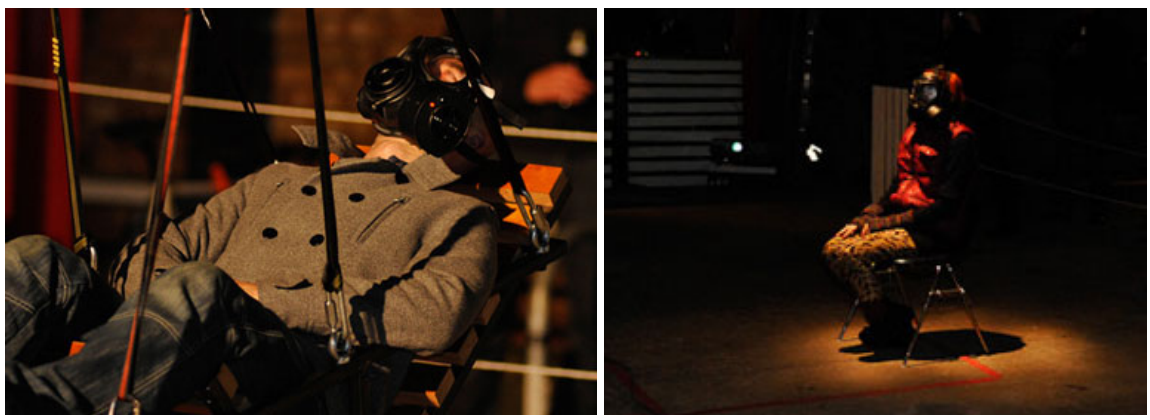

Fig. 3. Left: Participant riding the swing whilst wearing the gas mask. Right: Participant in seat, waiting for next rider to mount.

of immersion, but which still allowed for playful interaction between participants. To accentuate the atmosphere of the experience, the event took place after dark. We also used a wireless microphone attached into the gas mask to collect the sound of participants breathing, and used a powerful amplifier to fill the event space with this sound.

A final element of the event relates to the sensitizing concept loss of control which emerged from the workshop described above. Rather than just allowing participants to control their own experience on the ride, every participant in Breathless actually moves through three different pre-defined roles, allowing them to experience different aspects of control. In general, movement through Breathless is tightly choreographed by event staff, and works as follows:

1. Participants join a queue take part, and arrive at a desk, where they are fitted with an appropriately-sized gas mask, fitted with a breathing sensor, which has been sterilised if previously used

2. This breathing sensor is then activated, and a visualisation of the participant's breathing appears on a very large projection screen which is visible to all event attendees. This projection screen integrates visualisations of live breathing data being collected from all participants currently wearing gas masks

3. The participant is escorted to a position from which they can observe the operation of the ride (which at this point is being controlled by other participants)

4. The participant is then assisted to mount the cradle, and their movements are controlled for a while by the participant who has just vacated it (and who is now sitting in a chair next to it, as shown in the photograph on the right of figure 3 )

5. At some point, control is then switched to the participant who is in the cradle, whose breathing then influences their own movements on the ride for a while.

6. Finally, the participant in the cradle dismounts, and takes the now-vacant position in this seat to control the next rider.

\subsection{Collection and Analysis of Material during Breathless}

Breathless was designed and constructed over a two-week period, and opened to the public on a single evening, where it was experienced by over 50 participants. 
Throughout the process of conducting Breathless, we collected a variety of material for later analysis. These included semi-structured interviews with twenty-four participants, ambient video recorded from a number of viewpoints within the exhibition space, and regular interviews with designers during the two-week design process. Much of this material has since been transcribed and analyzed. We now present a number of elements of this analysis, structured by the sensitizing concepts introduced in section 5. This interview material has provided insights that will guide the future of development of Breathless, and other similar experiences. We return to it in the final section of this paper, where we discuss wider issues inherent in designing novel playful systems.

\subsubsection{Danger and Fear}

A number of elements in Breathless were selected for their potential to create fearful, intense experiences, but with no real threat of danger to our participants. For example, our use of gas masks seemed to create the potential for uncomfortable feelings of claustrophobia, and we wondered whether the height that the swing seat could rise to might be emotionally uncomfortable for riders, especially given the amount of momentum which is inherent in the system. We asked participants about these issues in our interviews, and have since collated responses.

Although some participants were clearly made uncomfortable by wearing a gas mask, an analysis of responses suggests that there are actually very subtle differences in perception and past experience between participants that influenced their experience, raising an interesting issue of how to design around the concept of danger and fear in the future. For example, one participant had very poor eye-sight, and had to remove his glasses to put the gas mask on - he then described the resultant hazy view that he had from the swing as being "nerve-wracking", but enjoyable because of this intensity. In contrast, a number of participants who were experienced scuba divers described how wearing the gas mask actually felt enjoyable, because it reminded them of diving. However, one participant, who had been diving once and who had hated it, described how the gas mask reminded her of this unpleasant experience. In terms of the height that the swing reached, most participants stated that this was not sufficient to scare them, and that they would have liked it to have gone higher. However, one participant reported being so scared of how high that he was going that he felt like holding his breath, to make sure that it did not go any higher. Finally, although many participants reported feeling claustrophobic when they first put the mask on, a number described how, once they relaxed into this experience, they actually started enjoying the experience of wearing it. In relation to this, one participant described how the mask made her feel like she was in a space of her own, whilst another participant described the experience as like being alone in a bubble, and implying that this was an interesting and comfortable situation to be in.

\subsubsection{Control}

Clearly control is a key part of the experience of Breathless, with participants being in control when they first mount the swing, then losing control at some point in the experience, and then being given the chance to exert control over another participant after they have vacated it. One participant described this final phase as being "powerful", especially given that the participant he was controlling was his friend. 
Another participant described Breathless as a very playful experience, because of the option of either "making the other person more thrilled by their experience" or "teasing them to experience something a bit more". Most people described wanting to give other participants a nice ride, although one participant described wanting to create "really rough high frequencies and fluctuations so the person would hopefully be a bit more freaked out". One participant described trying to be really careful when controlling the ride of a participant who appeared scared, whilst other participants described the added interest of trying to control someone that they already had a relationship with, such as friends, brothers or sisters. When being controlled by others, one participant reported a bad experience, given by a person who "didn't really cope with the concept ... it was more like 'bump, bump, bump', it was more like a wobbly chair". However, others described really pleasant experiences: "it was good, because he really had the knack of it, like he was doing it really smoothly". Interestingly, some participants tried to communicate with the person who was controlling them, but found this difficult, because the gas mask restricted communication. In addition, because control of the swing is somewhat indirect, a number of participants reported never fully feelings sure about when control shifted from the person sitting on the chair to them, though this lack of certainty seems to have been interesting in its own right.

\subsubsection{Re-appropriation}

Participants were only given a few minutes in each of the three roles in Breathless, giving little time for the kinds of re-appropriation described in section 5. However, interview comments by certain participants have helped us to think about reappropriation in more depth; in particular a number of interviewees described not being able to work out what the purpose of the Breathless setup was, and therefore having to experiment for a while before working out how to use it (and enjoying this experimental part of the experience). These comments remind us of work on ambiguity in design (for example, [33]). We wonder whether designs that are more ambiguous are more amenable to re-appropriation - or, alternatively, whether the reappropriation of designs that have an apparently clear purpose is more enjoyable.

\subsubsection{Skill}

From our own experimentation, we expected participants to take some time to learn how to control the swing in Breathless, and interview material provides some detail about the challenge of this process. An analysis of this material suggests that some participants sometimes drew on previous experience to learn how to control the swing, alongside experimentation with their breathing and its effects on the system. For example, one participant described how martial arts training had led him to consider the ration between his in-breath and his out-breath, which led him to experiment with varying this ratio whilst riding the swing. Other participants described experimenting with the smoothness of their breathing, with the point in the swing-cycle that they breathed at, and with breathing with either their mouth or their nose. One participant stated that he had a bad cold, and described how this made it hard to control the ride. Other participants described having a lack of an intrinsic ability to keep a rhythm, and suggested that this made it harder to get the swing moving higher. Finally, some participants reported that it was much easier to judge 
the movement of the swing when they were sitting beside it, controlling someone else. In comparison, when riding the swing, they had little vision, so had to try and sense the position of their bodies, by paying attention to the weight that they were putting on the swing-seat, their sense of balance and the visceral feelings of acceleration that were induced in their stomach.

\subsubsection{Throughput}

For the designers of Breathless, throughput was a key issue when preparing for the public event. A large number of participants were expected, and there was no clear incentive for riders to dismount the swing, and to give way to others. The movement of participants through three roles was a clear response to this issue, and movement between these roles was created in a variety of ways. Primarily, event staff were in charge of the electronic linkage between breathing sensor and ride movement, and could disconnect this when a participant had experienced a reasonable amount of time on the swing. Other event staff were then on hand to move participants through the positions that related to roles. Such a high level of choreography contrasts strongly with the situation in a typical playground, in which throughput is managed through social interaction; clearly, therefore, although choreography is one tactic for maintaining throughput, other tactics may be worth exploring.

\subsubsection{Spectatorship}

A number of participants reported how the experience of spectating Breathless influenced their experience of taking part. For example, one participant reported watching the visualization of her breathing that was displayed on the projection screen, and learning how the trace responded to in-breaths and out-breaths. Another described being made to feel nervous by the spectacle of a person in a gas mask, swinging backwards and forwards in the dark. One participant noticed that her breathing appeared very different to other participants, and practiced making it more similar - which then helped her on the ride. Finally, another participant reported swearing by mistake, and then realizing that this had been heard by the whole of the audience - which therefore made her feel self-conscious.

\section{Discussion - Lessons Learned, and Future Work}

In this paper, we have presented a set of sensitizing concepts derived from an analysis of the playground, and illustrated their creative application to Breathless, an installation which represents a dramatic evolution of the playground swing. In this section, we now present some brief reflections on the knowledge that has been gained through this process, structured through two core themes - accounting for individuality and considering trade-offs between concepts. We also provide a commentary considering the relationship between inclusive design and playful interaction.

\subsection{Accounting for Individuality}

A key observation in relation to the research material gathered through Breathless is the impact of participant history and personality on the nature of their experience in 
this event. To give two examples: participants who had previously had pleasurable experiences whilst scuba diving seemed more likely to enjoy the isolating feeling of wearing the gas-mask during the event, and participants who had worn gas-masks at school (possibly through drills designed to practice response to chemical attacks) seemed more likely to at least be comfortable with wearing the mask. There also seemed to be some differences between participants in relation to their perceptions of the height that the swing rose to, with some participants being scared by this, but with other participants wanting a more extreme experience than we could provide. Collectively, these observations hint at the challenge of designing playful experiences that are enjoyable and beneficial to those that take part in them. In relation to these observations, two opposing tactics suggest themselves:

Aim for universality: This tactic, which may be closest to traditional playground design, is to aim for experiences that are as universal as possible. The concepts presented above provide a resource for working within this tactic, but it must present a significant challenge due to the nature of individuality. Universal designs might be relatively generic (like most playground equipment). Designers might also consider approaches such as focusing on installations that can be dynamically adapted to the personality and abilities of their users, to maximize the range of individuals for whom they are relevant.

Design for specific groups: Abandoning universality allows the freedom to design for specific groups of individuals. In relation to Breathless, for example, we could imagine a variant that provided a far more thrilling experience for those who would appreciate it (i.e. an approach which emphasizes danger and fear), or a second variant that was more focused on supporting re-appropriation. This tactic raises an issue of how to identify groups that are interesting to design playful systems for. It also raises issues such as how to profile participants and allocate them to groups.

\subsection{Considering Trade-Offs between Concepts}

A second issue that is highlighted by material collected during Breathless is the potential trade-offs that might have to be made when using the concepts presented in this paper as a resource for design. In Breathless, for example, a clear trade-off had to be made between allowing participants sufficient time on the swing to start to think about re-appropriation and maintaining a sufficient throughput to give all attendees at the event a chance of getting involved. This relates to the nature of the event, which only ran for one evening, and which presented a novel experience which many attendees wished to sample. Playgrounds negotiate this trade-off differently - by often being continuously accessible (and therefore reducing contention) and by relying upon human interaction to resolve contention. Equally, however, contention in the playground can lead to some users being denied access to equipment.

Other trade-offs undoubtedly exist between these concepts, and exploring them seems to be an interesting direction for research. When a trade-off has to be made, it may be that investigations into the available tactics within that trade-off could provide benefits. 


\subsection{Inclusive Design in Relation to Playful Systems}

Finally, we wanted to acknowledge the potential importance of inclusive design and playful systems, in relation to the concepts that we have outlined above, and especially in relation to play that encourages physical and social interaction. In particular, we wanted to highlight issues around the concept of danger and fear. Even in today's risk averse societies, playgrounds still offer an opportunity for the ablebodied to experience the pleasures of flirting with danger, albeit with some safeguards to help avoid injury, such as play surfaces to fall onto that are soft in comparison to older materials such as concrete or gravel. However, a number of authors have argued that, when seeking to design for individuals with disabilities, there is often an excessive emphasis on safety, which carries a risk of denying worthwhile experiences around danger and fear to these individuals [34]. When seeking to design within the set of concepts presented in this paper, there is therefore an interesting challenge of how to ensure that as wide a group of individuals as possible are given the opportunity of gaining benefit from playful systems that embed these concepts. In particular, we might pose the question of how to design playful systems that are amenable to interaction for individuals with disabilities, but which still allow for creative re-appropriation, and which still allow for controlled elements of danger, for those participants that wish to take risks.

\section{Conclusions}

Playgrounds provide a relatively universal experience which involves physical and social interaction, and which encourage play. Our analysis of a workshop focused on the playground has provided significant inspiration for the design of Breathless, a novel interactive experience, and we hope that it will provide inspiration for others. We can imagine future work that involves novel design, and which draws on these concepts. We can also imagine future work that uses them as an analytical framework when considering existing design.

Acknowledgments. This work was supported by the Horizon Digital Economy Hub (EP/G065802/1).

\section{References}

1. Huizinga, J.: Homo Ludens: A study of the play element in culture. The Beacon Press, Boston (1950)

2. Gaver, W.: Designing for Homo Ludens. I3 Magazine (12) (2002)

3. Bekker, T., Sturm, J., Eggen, B.: Designing playful interaction for social interaction and physical play. Personal and Ubiquitous Computing 14, 385-396 (2010)

4. Nielsen, R., Fritsch, J., Halskov, K., Brynskov, M.: Out of the box: exploring the richness of children's use of an interactive table. In: 8th International Conference on Interaction Design and Children (2009)

5. Kizony, R., Katz, N., Weiss, P.: Adapting an immersive virtual reality system for rehabilitation. Journal of Visualization and Computer Animation 14, 261-268 (2003) 
6. Online guide to the use of the Nintendo Wii in physical rehabilitation, http: / / www.wiihabilitation.co.uk/

7. Walker, B., Schnädelbach, H., Rennick Egglestone, S., Clarke, A., Ng, M., Wright, M., Rodden, T., Benford, S., French, A.: Augmenting amusement rides with telemetry. In: International Conference on Advances in Computer Entertainment Technology (2007)

8. Marshall, J., Rowland, D., Rennick Egglestone, S., Benford, S., Walker, B., McAuley, D.: Breath control of amusement rides. In: 29th International Conference on Human Factors in Computer Systems (2011)

9. Jones, K., Wills, J.: The invention of the park: from the Garden of Eden to Disney's Magic Kingdom. Polity Press, Cambridge (2005)

10. Internet article on adult playgrounds, http: / / www. independent.co.uk/news / uk/home-news / eastbourneto-provide-playground-for-the-elderly-1029067.html

11. Solomon, S.: American playgrounds: Revitalizing community spaces. UPNE, New England (2005)

12. Playground designers' website, http: / / www.schoolplaygrounddesigners.co.uk/

13. Ladd, G., Price, J., Hart, C.: Predicting preschoolers' peer status from their playground behaviors. Child Development 59(4), 986-992 (1988)

14. Barbour, A.: The impact of playground design on the play behaviors of children with different levels of physical competence. Early Childhood Research Quarterly 14(1), 75-98 (1999)

15. Sturm, J., Bekker, T., Groenendaal, B., Wesselink, R., Eggen, B.: Key issues for the successful design of an intelligent interactive playground. In: 7th International Conference on Interaction Design for Children (2008)

16. Seitnger, S., Sylvan, E., Zuckerman, O., Popovic, M., Zuckerman, O.: A new playground experience: going digital? In: Alt. Chi at the 24th Annual SIGCHI Conference on Human Factors in Computing Systems (2006)

17. Pares, N., Durany, J., Carreras, A.: Massive flux design for an interactive water installation: WATER GAMES. In: 2nd International Conference on Advances in Computer Entertainment Technology (2005)

18. Delbruck, T., Whatley, A., Douglas, R., Eng, K., Hepp, K., Verschure, P.: A tactile luminous floor for an interactive autonomous space. Robotics and Autonomous Systems 55, 433-443 (2007)

19. Soler-Adillon, J., Pares, N.: Interactive slde: An interactive playground to promote physical activity and socialization of children. In: Alt. Chi at the 27th Annual SIGCHI Conference on Human Factors in Computing Systems (2009)

20. Misund, G., Holone, H., Karlsen, J., Tolsby, H.: Chase and catch - simple as that? Oldfashioned fun of traditional playground games revitalized with location-aware mobile phones. In: 6th International Conference on Advances in Computer Entertainment (2009)

21. Derakhshan, A., Hammer, F., Hautop Lund, H.: Adapting playgrounds for children's play using ambient playware. In: IEEE/RJS International Conference on Intelligent Robots and Systems (2006)

22. Blumer, H.: What is wrong with social theory? American Sociological Review 18, 3-10 (1954)

23. Holloway, I.: Basic concepts for qualitative research. Wiley-Blackwell (1997)

24. Bowen, G.: Grounded theory and sensitizing concepts. International Journal of Qualitative Methods 5(3) (2006) 
25. Crabtree, A., Rodden, T., Hemmings, T., Benford, S.: Finding a place for Ubicomp in the home. In: Dey, A.K., Schmidt, A., McCarthy, J.F. (eds.) UbiComp 2003. LNCS, vol. 2864, pp. 208-226. Springer, Heidelberg (2003)

26. Gaver, W., Bowers, J., Boucher, A., Gellerson, H., Pennington, S., Schmidt, A., Steed, A., Villars, N., Walker, B.: The drift table: designing for ludic engagement. In: 22nd Annual SIGCHI Conference on Human Factors in Computing Systems (2004)

27. Neustaedter, C., Bernheim Brush, A.: "LINC-ing" the family: the participatory design of an inkable family calendar. In: 24th Annual SIGCHI Conference on Human Factors in Computing Systems (2006)

28. Free Play, http: //www. freeplaydesigns.com/

29. Learning Science Research Institute, http: / /www. Isri .nottingham.ac.uk/

30. Aerial, http://www.aerial.fm/

31. Boyatzis, R.: Transforming qualitative information: thematic analysis and code development, 1st edn. Sage publications, Thousand Oaks (1998)

32. Benford, S., Giannachi, G., Koleva, B., Rodden, T.: Temporal trajectories in shared interactive narratives. In: 26th Annual SIGCHI Conference on Human Factors in Computing systems

33. Gaver, WW., Beaver, J., Benford, S.: Ambiguity as a resource for design. In: 21 st Annual SIGCHI Conference on Human Factors in Computing Systems (2003)

34. Inclusive design case studies, http://www.designcouncil.info/inclusivedesignresource/benwil son/intro.html 